\title{
New developments in the pathology of malignant lymphoma: a review of the literature published from August to November 2009
}

\author{
J. Han van Krieken
}

Published online: 17 December 2009

(C) Springer-Verlag 2009

\section{Biology of lymphoma}

The pathogenesis of malignant lymphomas remains poorly understood. Several approaches to detect the genes involved are available. Bric et al. [1] focus on the detection of tumor suppressor genes by using RNA interference of specific gene products in a known mouse model for lymphoma development. They detected more than 10 new candidate tumor suppressor genes, showing the validity of their functional approach. In a similar approach in a different mouse model, Meacham et al. [2] found many new gene alterations in a mouse lymphoma, several of which involved genes associated with cell motility. They were also able to show that these genes were bona fide drug targets.

Gloghini et al. [3] studied 14 cell lines and 89 lymphoma tissues for expression of histone deacetylases (HDAC). In cell lines, low expression HDAC6 was associated with growth inhibitory effects of HDAC inhibitors, but it is rarely expressed in tissue samples of diffuse large B cell lymphoma (DLBL) and Hodgkin lymphoma (HL).

\section{B cell lymphomas}

A crucial element in cancer cells is the unlimited potential to replicate; thus, cancer cells need telomerase activity for synthesizing telomeric DNA. Most differentiated cells lack this activity, but in cancer cells, there is low-level expression due to altered methylation status of the gene.

\section{J. H. van Krieken $(\bowtie)$}

Department of Pathology,

Radboud University Nijmegen Medical Centre,

P.O. Box 9101, 6500 HB Nijmegen, The Netherlands

e-mail: j.vankrieken@pathol.umcn.nl

In B lymphocytes, the situation is different since they have telomerase activity and normal methylation status. Bougel et al. [4] show that by downregulating Pax5, this activity disappears, indicating the importance of that gene for the potential of normal B cells to undergo many cell divisions.

The TCL-1 gene is often deregulated in B cell lymphomas due to hypermethylation of several genes. Balatoni et al. [5] show that one of these Stk39-encoded proteins (SPAK), which regulates stress response, is downregulated in B cell lymphomas resulting in apoptosis resistance.

Chromosomal breaks are dangerous to cells; nevertheless, they occur often in germinal center B cells. Zhou et al. [6] found in a mouse model that MDM2, which induces apoptosis in cells with chromosomal breaks, is downregulated in germinal center B cells due to lack of expression of IFN regulatory factor 8 and thus tolerating chromosomal breaks needed for B cell antigen receptor rearrangement.

It is still unclear why the Epstein-Barr virus (EBV) can result in so many different diseases. Lorenzetti et al. [7] linked genomic variation of the BZLF1 gene of the virus to 13 cases of lymphoma and 10 of infectious mononucleosis in children. They were able to find significance but no absolute difference indicating that other genes or factors are important too.

Follicular lymphoma (FL) can have various amounts of diffuse growth areas. Higashi et al. [8] show that the expression of CD44 and variants is associated with diffuse areas.

In primary mediastinal large B cell lymphoma and HL, inactivating mutations in SOCS1, an inhibitor of Janus kinase/signal transducers and activators of transcription (JAK/STAT) signaling, contributes to deregulated STAT activity. Mottok et al. [9] show that these mutations, which are preferentially targeted to somatic hypermutation hotspot motifs and frequently inactivating, occur at low level in 
normal germinal center cells, indicating that they are due to the somatic hypermutation machinery. This was confirmed by the finding that a quarter of diffuse large B cell lymphoma (DLBCL) and FL carried SOCS1 mutations and that only rare mutations are present in Burkitt lymphoma, plasmacytoma, and mantle cell lymphoma (MCL) and none in tumors of a non-B cell origin.

\section{$\mathrm{T}$ cell lymphoma}

A specific diet is associated with several forms of cancer, but there are limited data on the association of food products and lymphoma development. An interesting study of Mannini et al. [10] shows that mice fed with maize oil have a lower lymphoid infiltration of a $\mathrm{T}$ cell lymphoma cell line compared with mice that are fed with fish oil when an aggressive cell line was used, but there were no differences in case of a less aggressive cell line. The exact mechanism remains unclear however.

Anaplastic lymphoma kinase (ALK)-positive anaplastic large cell lymphoma (ALCL) lacks tumor necrosis factor (TNF)-alpha expression likely due to promoter methylation. Demethylation of the promoter in cell lines led to expression. ALCL cell lines have the TNF-alpha receptor, and exogenous TNF-alpha induces apoptosis in these cells. These data combined suggest that treatment of ALCL patients with a DNA methyltransferase inhibitor might be an effective approach (Zhang et al. [11]).

Eckerle et al. [12] investigated isolated tumor cells from ALCL (five ALK-positive, four ALK-negative, and seven cutaneous) and compared the results with those from HL and from subsets of $\mathrm{T}$ and natural killer (NK) cells. The results indicate that ALCL derives from activated T cells, but they had neither a CD8 nor a CD4 gene profile; in fact, many $\mathrm{T}$ cell genes were downregulated. It was remarkable that there were little differences between all studied lymphomas even though HL is a B cell neoplasia. It is therefore questionable whether this approach gives good insight in the cell of origin of a lymphoma.

\section{Epidemiology of lymphoma}

Loberiza et al. [13] investigated whether urban or rural lymphoma patients have better outcome and whether this was associated with care given by a university or a community hospital. In a population-based cohort of 2,330 patients, they found limited differences, indicating the good organization of care overall. Nevertheless, rural patients with low and intermediate risk disease treated in a community hospital had a higher risk of death; in high risk patients, outcome was better in a university hospital for urban patients.
Ocular marginal zone lymphomas may be associated with Chlamydia psittaci. According to Carugi et al. [14], this the case in an Italian region (17\%) but not in a Kenyan region $(0 \%)$.

\section{Defining entities}

Hodgkin lymphoma and B cell lymphomas

There are clinical, morphological, and phenotypical similarities between HL and primary mediastinal DLBL (PMLBCL). In the 2008 World Health Organization (WHO) classification, a separate chapter is dedicated to cases with features of both, and presently, it remains open for discussion whether these intermediate cases represent an entity. Miles et al. [15] investigate the growth factor receptor-bound protein 2 (Grb2), a molecule that mediates $\mathrm{B}$ cell receptor signaling pathways. In reactive lymphoid tissues, Grb2 was expressed in the cytoplasm of B cells and histiocytes but not $\mathrm{T}$ cells. Strong cytoplasmic Grb2 expression was seen in FL, chronic lymphocytic leukemia/ small lymphocytic lymphoma (CLL/SLL), splenic marginal zone lymphoma (SMZL), PMLBCL, DLBL, and nodular lymphocyte predominant HL. In contrast, only $10 \%$ of the classical HL showed Grb2 expression in the neoplastic cells. These findings support a role for growth factor receptor-bound protein 2 in the diagnostically challenging workup of classical HL versus PMLBCL.

Earlier, Wu et al. [16] had found that JAK2 signaling is increased in PMLBCL, and thus, they analyzed whether JAK2 mutations can be found in 31 of these cases, or in four HL, but found no mutation in JAK2 V617F or exon 12. It remains open to which mechanism upregulates JAK2 in PMLBCL.

Molecular alterations are increasingly important for treatment choices in CLL/SLL. Garcia et al. [17] tried to detect morphological features that indicate certain gene alterations in these cases. Based on the morphological, phenotypical, fluorescence in situ hybridization (FISH), and mutational data of 41 cases, they conclude that morphological features are not reliable in predicting genetic status even though there is an association between strong ZAP staining and unmutated immunoglobulin heavy chain.

SMZL is difficult to diagnose, since morphology is variable; there is no specific immunophenotype, and involvement of hepatitis $\mathrm{C}$ is present in a minority of cases. The del 7 is common, but not specific. Based on a comparative genomic hybridization (CGH) array study of 34 patients, 12 of whom were hepatitis C-positive, the most frequent copy number alterations involved chromosomes 7 and 17 (21\% and 24\%, respectively). Except for Xp gain, no differences in common alterations were found between 
hepatitis $\mathrm{C}$ virus-positive and hepatitis $\mathrm{C}$ virus-negative cases. Unmutated status of the $\operatorname{IgV}(\mathrm{H})$ gene was related to $\operatorname{del}(7 q)$ and $\operatorname{dup}(12 q)$. Poor prognosis was associated with $\operatorname{del}(7 q)$ and $\operatorname{del}(17 p)$.

MCL remains a widely studied lymphoma, and in my next review, I expect to be able to shed new light on cyclinD1-negative cases. Mangseth et al. [18] found that CyclinD3 is lower expressed in MCL than in other small cell lymphomas, and thus, the ratio cyclinD1/D3 is a better diagnostic marker. This was needed in their series since there was considerable overlap between MCL and the other cases with respect to cyclinD1, a surprising finding. Increasingly, cyclinD1-negative cases are described, and Stefancikova [19] describes two such cases that have the $t(11 ; 14)$. An important new marker for MCL may be sox 11 since it is positive in MCL, regardless of the presence of $\mathrm{t}(11 ; 14)$ and cyclinD1 staining, although it is positive in multiple myeloma, hairy cell leukemia (HCL), and BL as well (Chen et al. [20]). Gualco analyzed 127 cases of MCL for an aberrant phenotype. Since all their cases expressed cyclinD1, they may have missed negative cases. All their cases were CD20-positive, 96\% had CD5, and 35\% were positive for MUM1, 12\% for Bcl6. CD10 was positive in $10 \%$ to $20 \%$ of the cells in only three cases. Finally, Navarro et al. [21] confirm that MCL is biologically heterogenous since they found differences in miRNA expression and chromosomal alterations between nodal and leukemic cases. All these data indicate that MCL is on the one hand a prime example of a well-characterized entity, but on the other hand, this entity is still heterogenous and contains cases with aberrant features.

About $5 \%$ of myelomas carry the $t(14 ; 16)$ involving the c-Maf gene, but there is little information on the expression pattern of this transcription factor. Natkunam et al. [22] found that it is expressed in about $4 \%$ of myelomas, in HCL (4/4), and in more than half of the T cell and NK/T cell neoplasias (24/42 and 49/97, respectively).

Plasmablastic lymphoma, extensively discussed at the recent excellent SH/EAHP workshop in Cleveland, remains a controversial entity. Bogusz et al. [23] describe three cases that have a MYC/IgH translocation out of the nine cases that they have seen in their institute. All three patients had HIV with a very low number of CD4 cells in their blood, and all cases had EBV but no HHV8. The prognosis was very poor. Also in other immunodeficient states, one sees lymphoproliferations with plasma cell differentiation, but full plasmacytoma morphology is rare in posttransplant cases. Richendollar et al. [24], from the Cleveland Clinic, describe four such cases, all arising extramedullary. These cases had arisen late after transplantation (mean 7 years); two of the four had EBV; they were morphologically and phenotypically very similar to plasmacytoma in immunocompetent individuals, but bone lesions did not occur.
Three of the patients responded well to reduction of immune suppression.

Kalungi et al. [25] were able to study 51 cases of BL from Uganda and found no mutations of the RBL2 gene but that about $85 \%$ of them expressed nuclear $\mathrm{pRb} 2$, even though this is a marker of growth arrest. Apparently, the $m y c$ dysregulation overcomes this growth arrest.

\section{T cell lymphomas}

Another well-defined entity is the ALK-negative ALCL. Lu et al. [26] report four adult cases that present with extensive peripheral blood and bone marrow involvement, a feature so far mainly described in children. These cases have a very poor outcome.

\section{Cutaneous lymphomas}

The CD30-positive cutaneous lymphomas may arise primarily or after transformation from mycosis fungoides (MF). PhamLedard et al. [27] analyzed 54 cases for rearrangement of the IRF4 gene using FISH. They observed a split FISH signal pattern indicating a translocation in six out of 23 ALCL (26\%) and two out of 11 transformed MF (18.2\%) cases. The IRF4 expression was not correlated with the presence of IRF4 alteration in ALCL or T-MF. In contrast to the title of the study, these data therefore do not indicate that these cases represent a specific subgroup of cutaneous lymphomas.

\section{New entities/subtypes}

Rarely, HL develops after transplantation. Adams et al. [28] compared eight such cases with classical HL developed in immune competent individuals. All cases expressed CD15, CD30, and LMP1. The B cell markers BOB-1, Oct2, CD79a, and CD20 were more commonly expressed in posttransplant HL versus cHL $(100 \%, 86 \%, 50 \%$, and $38 \%$ in ptHL compared to $6 \%, 14 \%, 10 \%$, and $33 \%$ in cHL, respectively); all ptHL expressed phosphoinositide 3-kinase versus $81 \%$ of cHL; $2 / 6$ (33\%). These limited differences do not indicate that these cases need a different approach.

Raparia et al. [29] describe the data from 16 patients with intraocular lymphoma and demonstrate that these can be adequately classified according to the WHO classification. DLBL, CD10-negative and most likely of nongerminal center B cell-like subgroup, is the most common subtype of non-Hodgkin lymphoma in this site, in contrast to ocular adnexal lymphoma for which MALT lymphoma is the most common subtype.

A multicenter group approached the problem of separating germinal center from activated B cell lymphomas. Using the 
antibodies GCET1, CD10, BCL6, MUM1, FOXP1, BCL2, MTA3, and cyclin D2, they were able to create an algorithm that predicts the distinction with $93 \%$ accuracy, much better than the $80 \%$ of the Hans algorithm (Choi et al. [30]).

By comparing 22 cases of DLBL with a high number of histiocytes with 96 cases of usual DLBL, Wada et al. [31] showed that these had a more favorable prognosis and more often EBV (about $20 \%$ versus $5 \%$ ) but had no other specific markers.

Bhagavathi et al. [32] did an in depth pathological study into 21 cases of primary bone DLBL. Since the phenotype, genetic changes, and subtype (GCB versus activated $B$ ) were highly variable, this is not a separate entity.

Miranda et al. [33] add additional cases to the increasing number of breast implant associated ALK-negative ALCL. Out of their six primary breast ALCL, four were ALKnegative, and three of them associated with a breast implant. These had a very good outcome, but it was remarkable that one was a patient with a previous ALCL of the skin.

Kong et al. [34] describe nine cases of cutaneous ALCL with many neutrophils or eosinophils. These cases can be difficult to diagnose but are further quite similar to regular cutaneous ALCL. There were too few cases to give an idea on prognostic impact of this finding.

\section{Pitfalls in lymphoma diagnosis}

New immunomodulating agents are increasingly used and can be associated with lymphoproliferations, often EBV-positive. Hasserjian et al. [35] collected 18 such cases, including six B cell lymphomas, two T cell lymphomas, three classical HL, and seven atypical lymphoproliferations. The results show that these cases are similar to posttransplant cases and are often very similar to regular lymphomas, so that knowledge of the clinical data is crucial.

Kan et al. [36] describe three difficult to diagnose splenic lymphomas; all three were in patients treated with corticosteroids before the splenectomy was performed, indicating that such treatment affects the morphology of lymphomas.

\section{Prognostic factors in lymphoma}

The human germinal center-associated lymphoma gene (HGAL) has prognostic value in DLBL, and thus, Azambuja decided to study it in HL as well. In 232 patients with HL, 188 had staining for HGAL in their tumor tissue. The patients had a more than $82 \% 5$-year survival in contrast to $67 \%$ in HDAL-negative cases. In a similar study in 280 cases, Muenst et al. [37] looked for expression of programmed death-1 (PD-1) and found that the number of PD-1-positive cells and their location in the tissue were related to HL subtypes and that patients with a high number of these cells have a poorer outcome, whereas those with a high number of FoxP3-positive cells have a better outcome.

Proliferation rate is an important prognostic factor in many tumors, including MCL. The assessment of the proliferative index is however rather subjective. In an important paper, including many experienced European hematopathologists, Klapper et al. [38] give a precise guideline based on a detailed interobserver study using different methods, which is relatively easy to follow, and is based on counting Ki67positive cells among 200 tumor cells.

Since vessel targeting has become an important approach in the management of patients with solid tumors, interest in the vascularization of lymphomas has increased as well. Gratzinger et al. [39] studied vascularization parameters in 162 de novo DLBL patients treated with R-CHOP, including vessel density, vascular endothelial growth factor (VEGF), and its receptors' expression. There was an association of VEGFR1 with longer overall survival, and the authors postulate that VEGFR1 may oppose autocrine VEGFR2 signaling in DLBCL by competing for VEGF binding. In contrast to prior results with chemotherapy alone, microvessel density was not prognostic with RCHOP-like therapy.

Gualco et al. [40] studied 16 pediatric and adolescent nodal DLBL and conclude that they are mainly of the germinal center type, with a generally good outcome despite the frequent expression of BCL-2 and the presence of $c-M Y C$ translocation. TCL1 expression seems to be associated with a good clinical outcome, whereas MUM1 expression predicts a poor clinical outcome. Obviously, data on such low numbers need confirmation in larger series.

Obermann et al. [41] looked into the prognostic value of bcl-2 gene abnormalities and protein expression in DLBL, using tissue microarrays of 224 cases. They found 40 cases with a bcl-2 break and 66 with a gain and that they conclude that cases of the non-GC type with BCL2 gene aberration are accompanied by a significantly worse prognosis as opposed to cases without such gene abnormalities. Protein expression was not indicative for prognosis.

Youssif et al. [42] performed CGH-array in 15 cases of pediatric ALK-positive ALCL and found that patients with fewer imbalances had a better outcome but gains in two regions were associated with a poor survival. Also here, the low number of cases needs to be taken into account.

\section{Staging}

Increasingly FDG-PET is being used in staging and assessing treatment response in patients with malignant lymphoma. Imataki compared this method with CTscanning in 95 patients and found that the sensitivity and 
specificity of both methods is the same. Subgroup analysis shows that there may be differences between lymphoma types, but the numbers are small.

\section{Ancillary techniques}

Since it is easier to obtain cells rather than tissues from patients, increasingly cytology is being used for diagnosing or excluding cancer. This approach is becoming more reliable, thanks to several methods than can be applied to such specimens. Gupta et al. [43] analyze the morphology and texture of B cell lymphoma cells in 50 cytological preparations with morphometry. Using all the morphometric and textural parameters together, $83.3 \%$ of cells could be correctly classified to a particular NHL subtype. Although this is not reliable enough for routine practice and the study is based on a limited number of specimens, the approach may be refined and can be a promising adjunct. Nevertheless, Das et al. [44] show in a study of seven cases of ALCL that nuclear features can be extremely variable.

A more important role for cytology is the separation of benign lymph nodes from malignant ones, and a protein that is differentially expressed between these would be very welcome. According to King et al. [45], the insulin-like growth factor II mRNA binding protein 3 (IMP-3) is such a molecule. They immunohistochemically evaluated IMP-3 expression in normal lymphoid tissue and 141 lymphomas. In nonmalignant tissues, IMP-3 expression was restricted to germinal center B cells. Among lymphoid neoplasms, HL demonstrated the highest percentage of positive cases $(26 / 26$, $100 \%$ ) often with bright staining. BL was positive in 10 $(83 \%)$ of 12 cases with moderate to bright staining. Although FL was also positive in a high percentage of cases $(12 / 15$, $80 \%$ ), the intensity was exclusively weak to moderate. Although 22 (85\%) of 26 of DLBL were positive for IMP3 , there was wide variability in staining intensity, which did not correlate with classification into activated $\mathrm{B}$ cell versus germinal center B origin. In contrast, lower proportions (8$20 \%$ ) of other nongerminal center B lymphoma subtypes were IMP-3-positive. In situation where architecture is lacking, like in cytological preparations, this knowledge may come in useful, but more studies are needed.

Another technique that is increasingly used, especially when limited material is available, is flow cytometry. Gujral et al. [46] were able to compare flow cytometry data from blood and bone marrow samples with the primary lymphoma tissue of $356 \mathrm{~B}$ cell lymphoma patients. A limited panel of nine antibodies, namely CD19, CD5, CD23, CD10, FMC7, kappa, lambda, CD3, and CD20, could correctly identify $92 \%$ of cases, including CLL, FCL, MCL, and HCL. This very good result indicated that cytological specimens can be used, too.
The presence of a chromosomal translocation can facilitate the correct classification of a lymphoma. Nowadays, this is mostly done using split signal probes on tissue sections using immunofluorescence. Van Rijk et al. [47] demonstrate, in 540 lymphoma cases representing 11 lymphoma types, that a bright field approach is feasible and reliable, which brings this technique within the reach of each pathology laboratory, provided that well-trained and dedicated technicians and pathologists are involved. Although Monaco et al. [48] used the fluorescent approach, in principle their data indicate that ISH for chromosomal translocations can be used in cytology specimens as well. Of their 181 cases, FISH studies were performed in 106 cases $(59 \%)$. The indications for FISH studies were for subclassification (59 cases; 56\%) and a nondiagnostic result (47 cases; $44 \%$ ). Of the 59 cases submitted for subclassification, 23 cases $(39 \%)$ were successfully subclassified. From the 47 cases which were nondiagnostic, 26 cases $(55 \%)$ demonstrated an immunoglobulin heavy-chain gene rearrangement and/or chromosomal translocation, indicating malignant lymphoma.

The diagnosis of angioimmunoblastic $\mathrm{T}$ cell lymphoma (AITL) can be difficult, and the presence of CD3-negative and CD10-positive cells can be helpful although this finding is not restricted to this lymphoma entity. Zhang et al. [49] show that after sorting of these cells and clonality testing, in early stage of AITL, they were oligoclonal and became monoclonal as AITL progressed. These findings illustrate the differences between early and late lymphoma but also indicate that the diagnosis remains difficult even after the use of these extensive and expensive techniques.

\section{References}

1. Bric A, Miething C, Bialucha CU, Scuoppo C, Zender L, Krasnitz A, Xuan Z, Zuber J, Wigler M, Hicks J, McCombie RW, Hemann MT, Hannon GJ, Powers S, Lowe SW (2009) Functional identification of tumor-suppressor genes through an in vivo RNA interference screen in a mouse lymphoma model. Cancer Cell 16(4):324-335

2. Meacham CE, Ho EE, Dubrovsky E, Gertler FB, Hemann MT (2009) In vivo RNAi screening identifies regulators of actin dynamics as key determinants of lymphoma progression. Nat Genet 41(10):1133-1137

3. Gloghini A, Buglio D, Khaskhely NM, Georgakis G, Orlowski RZ, Neelapu SS, Carbone A, Younes A (2009) Expression of histone deacetylases in lymphoma: implication for the development of selective inhibitors. Br J Haematol 147(4):515-525

4. Bougel S, Renaud S, Braunschweig R, Loukinov D, Morse Iii HC, Bosman FT, Lobanenkov V, Benhattar J (2009) PAX5 activates the transcription of the human telomerase reverse transcriptase gene in $\mathrm{B}$ cells. J Pathol (in press)

5. Balatoni CE, Dawson DW, Suh J, Sherman MH, Sanders G, Hong JS, Frank MJ, Malone CS, Said JW, Teitell MA (2009) Epigenetic silencing of Stk39 in B-cell lymphoma inhibits apoptosis from genotoxic stress. Am J Pathol 175(4):1653-1661

6. Zhou JX, Lee CH, Qi CF, Wang H, Naghashfar Z, Abbasi S, Morse HC 3rd (2009) IFN regulatory factor 8 regulates MDM2 in germinal center B cells. J Immunol 183(5):3188-3194 
7. Lorenzetti MA, Gutiérrez MI, Altcheh J, Moscatelli G, Moroni S, Chabay PA, Preciado MV (2009) Epstein-Barr virus BZLF1 gene promoter variants in pediatric patients with acute infectious mononucleosis: its comparison with pediatric lymphomas. J Med Virol 81(11):1912-1917

8. Higashi M, Sugaya Y, Soeta S, Yokota A, Ishii G, Harigaya K (2009) CD44 expression during tumor progression of follicular lymphoma. Oncol Rep 22(5):1135-1140

9. Mottok A, Renne C, Seifert M, Oppermann E, Bechstein W, Hansmann ML, Kuppers R, Brauninger A (2009) Inactivating SOCS1 mutations are caused by aberrant somatic hypermutation and restricted to a subset of B cell lymphoma entities. Blood 114 (20):4503-4506

10. Mannini A, Kerstin N, Calorini L, Mugnai G, Ruggieri S (2009) Dietary n-3 polyunsaturated fatty acids enhance metastatic dissemination of murine $\mathrm{T}$ lymphoma cells. Br J Nutr 102 (7):958-961

11. Zhang Q, Wang HY, Bhutani G, Liu X, Paessler M, Tobias JW, Baldwin D, Swaminathan K, Milone MC, Wasik MA (2009) Lack of TNFalpha expression protects anaplastic lymphoma kinasepositive T-cell lymphoma (ALK+TCL) cells from apoptosis. Proc Natl Acad Sci USA 106(37):15843-15848

12. Eckerle S, Brune V, Döring C, Tiacci E, Bohle V, Sundström C, Kodet R, Paulli M, Falini B, Klapper W, Chaubert AB, Willenbrock K, Metzler D, Bräuninger A, Küppers R, Hansmann ML (2009) Gene expression profiling of isolated tumour cells from anaplastic large cell lymphomas: insights into its cellular origin, pathogenesis and relation to Hodgkin lymphoma. Leukemia 23(11):2129-2138

13. Loberiza FR Jr, Cannon AJ, Weisenburger DD, Vose JM, Moehr MJ, Bast MA, Bierman PJ, Bociek RG, Armitage JO (2009) Survival disparities in patients with lymphoma according to place of residence and treatment provider: a population-based study. J Clin Oncol 27(32):5376-5382

14. Carugi A, Onnis A, Antonicelli G, Rossi B, Mannucci S, Luzzi A, Lazzi S, Bellan C, Tosi GM, Sayed S, De Falco G, Leoncini L (2009) Geographic variation and environmental conditions as cofactors in Chlamydia psittaci association with ocular adnexal lymphomas: a comparison between Italian and African samples. Hematol Oncol (in press)

15. Miles RR, Mankey CC, Seiler CE 3rd, Smith LB, TeruyaFeldstein J, Hsi ED, Elenitoba-Johnson KS, Lim MS (2009) Expression of Grb2 distinguishes classical Hodgkin lymphomas from primary mediastinal B-cell lymphomas and other diffuse large B-cell lymphomas. Hum Pathol 40(12):1731-1737

16. Wu D, Dutra B, Lindeman N, Takahashi H, Takeyama K, Harris NL, Pinkus GS, Longtine J, Shipp M, Kutok JL (2009) No evidence for the JAK2 (V617F) or JAK2 exon 12 mutations in primary mediastinal large B-cell lymphoma. Diagn Mol Pathol 18 (3):144-149

17. Garcia CF, Hunt KE, Kang H, Babb A, Gale JM, Vasef MA, Reichard KK (2009) Most morphologic features in chronic lymphocytic leukemia/small lymphocytic lymphoma (CLL/SLL) do not reliably predict underlying FISH genetics or immunoglobulin heavy chain variable region somatic mutational status. Appl Immunohistochem Mol Morphol (in press)

18. Mangseth K, Helgeland L, Klos J, Molven A, Vintermyr OK (2009) Improved diagnostic segregation of mantle cell lymphoma by determination of cyclin D1/D3 expression ratio in formalinfixed tissue. Diagn Mol Pathol 18(3):150-155

19. Stefancikova L, Monlis M, Fabian P, Falhova I, Vasova I, Kren L, Macak J, Smardova J (2009) Complex analysis of cyclin D1 expression in mantle cell lymphoma: two cyclin D1-negative cases detected. J Clin Pathol 62(10):948-950

20. Chen YH, Gao J, Fan G, Peterson LC (2009) Nuclear expression of sox11 is highly associated with mantle cell lymphoma but is independent of $\mathrm{t}(11 ; 14)(\mathrm{q} 13 ; \mathrm{q} 32)$ in non-mantle cell B-cell neoplasms. Mod Pathol (in press)

21. Navarro A, Beà $\mathrm{S}$, Fernández V, Prieto $\mathrm{M}$, Salaverria I, Jares $\mathrm{P}$, Hartmann E, Mozos A, López-Guillermo A, Villamor N, Colomer D, Puig X, Ott G, Solé F, Serrano S, Rosenwald A, Campo E, Hernández L (2009) MicroRNA expression, chromosomal alterations, and immunoglobulin variable heavy chain hypermutations in Mantle cell lymphomas. Cancer Res 69(17):7071-7078

22. Natkunam Y, Tedoldi S, Paterson JC, Zhao S, Rodriguez-Justo M, Beck AH, Siebert R, Mason DY, Marafioti T (2009) Characterization of c-Maf transcription factor in normal and neoplastic hematolymphoid tissue and its relevance in plasma cell neoplasia. Am J Clin Pathol 132(3):361-371

23. Bogusz AM, Seegmiller AC, Garcia R, Shang P, Ashfaq R, Chen W (2009) Plasmablastic lymphomas with $\mathrm{MYC} / \mathrm{IgH}$ rearrangement: report of three cases and review of the literature. Am J Clin Pathol 132(4):597-605

24. Richendollar BG, Hsi ED, Cook JR (2009) Extramedullary plasmacytoma-like posttransplantation lymphoproliferative disorders: clinical and pathologic features. Am J Clin Pathol 132 (4):581-588

25. Kalungi S, Steine SJ, Wabinga H, Bostad L, Molven A (2009) $\mathrm{pRb} 2 / \mathrm{p} 130$ protein expression and RBL2 mutation analysis in Burkitt lymphoma from Uganda. BMC Clin Pathol 9:6

26. Lu Y, Zhao X, Wang E, Chen W, Huang Q (2009) ALK-negative anaplastic large cell lymphoma with extensive peripheral blood and bone marrow involvements manifested as "leukemic phase". Leuk Res (in press)

27. Pham-Ledard A, Prochazkova-Carlotti M, Laharanne E, Vergier B, Jouary T, Beylot-Barry M, Merlio JP (2009) IRF4 gene rearrangements define a subgroup of $\mathrm{CD} 30$-positive cutaneous $\mathrm{T}$ cell lymphoma: a study of 54 cases. J Invest Dermatol (in press)

28. Adams H, Campidelli C, Dirnhofer S, Pileri SA, Tzankov A (2009) Clinical, phenotypic and genetic similarities and disparities between post-transplant and classical Hodgkin lymphomas with respect to therapeutic targets. Expert Opin Ther Targets 13 (10): $1137-1145$

29. Raparia K, Chang CC, Chévez-Barrios P (2009) Intraocular lymphoma: diagnostic approach and immunophenotypic findings in vitrectomy specimens. Arch Pathol Lab Med 133(8):12331237

30. Choi WW, Weisenburger DD, Greiner TC, Piris MA, Banham AH, Delabie J, Braziel RM, Geng H, Iqbal J, Lenz G, Vose JM, Hans CP, Fu K, Smith LM, Li M, Liu Z, Gascoyne RD, Rosenwald A, Ott G, Rimsza LM, Campo E, Jaffe ES, Jaye DL, Staudt LM, Chan WC (2009) A new immunostain algorithm classifies diffuse large B-cell lymphoma into molecular subtypes with high accuracy. Clin Cancer Res 15(17):5494-5502

31. Wada N, Ikeda J, Kohara M, Ogawa H, Hino M, Fukuhara S, Kanamaru A, Sugiyama H, Kanakura Y, Morii E, Aozasa K (2009) Diffuse large B-cell lymphoma with a high number of epithelioid histiocytes (lymphoepithelioid B-cell lymphoma): a study of Osaka Lymphoma study group. Virchows Arch 455 (3):285-293

32. Bhagavathi S, Micale MA, Les K, Wilson JD, Wiggins ML, Fu K (2009) Primary bone diffuse large B-cell lymphoma: clinicopathologic study of 21 cases and review of literature. Am J Surg Pathol (in press)

33. Miranda RN, Lin L, Talwalkar SS, Manning JT, Medeiros LJ (2009) Anaplastic large cell lymphoma involving the breast: a clinicopathologic study of 6 cases and review of the literature. Arch Pathol Lab Med 133(9):1383-1390

34. Kong YY, Dai B, Kong JC, Lu HF, Shi DR (2009) Neutrophil/ eosinophil-rich type of primary cutaneous anaplastic large cell lymphoma: a clinicopathological, immunophenotypic and molecular study of nine cases. Histopathology 55(2):189-196 
35. Hasserjian RP, Chen S, Perkins SL, de Leval L, Kinney MC, Barry TS, Said J, Lim MS, Finn WG, Medeiros LJ, Harris NL, O'Malley DP (2009) Immunomodulator agent-related lymphoproliferative disorders. Mod Pathol 22(12):1532-1540

36. Kan E, Levy I, Benharroch D (2009) Splenic micronodular T-cell/ histiocyte-rich large B-cell lymphoma: effect of prior corticosteroid therapy. Virchows Arch 455(4):337-341

37. Muenst S, Hoeller S, Dirnhofer S, Tzankov A (2009) Increased programmed death-1+ tumor-infiltrating lymphocytes in classical Hodgkin lymphoma substantiate reduced overall survival. Hum Pathol 40(12):1715-1722

38. Klapper W, Hoster E, Determann O, Oschlies I, van der Laak J, Berger F, Bernd HW, Cabeçadas J, Campo E, Cogliatti S, Hansmann ML, Kluin PM, Kodet R, Krivolapov YA, Loddenkemper C, Stein H, Möller P, Barth TE, Müller-Hermelink K, Rosenwald A, Ott G, Pileri S, Ralfkiaer E, Rymkiewicz G, van Krieken JH, Wacker HH, Unterhalt M, Hiddemann W, Dreyling M, for the European MCL Network (2009) Ki-67 as a prognostic marker in mantle cell lymphoma - consensus guidelines of the pathology panel of the European MCL Network. J Hematop 2(2):103-111

39. Gratzinger D, Advani R, Zhao S, Talreja N, Tibshirani RJ, Shyam R, Horning S, Sehn LH, Farinha P, Briones J, Lossos IS, Gascoyne RD, Natkunam Y (2009) Lymphoma cell VEGFR2 expression detected by immunohistochemistry predicts poor overall survival in diffuse large $\mathrm{B}$ cell lymphoma treated with immunochemotherapy (R-CHOP). Br J Haematol (in press)

40. Gualco G, Weiss LM, Harrington WJ Jr, Bacchi CE (2009) BCL6, MUM1, and CD10 expression in mantle cell lymphoma. Appl Immunohistochem Mol Morphol (in press)

41. Obermann EC, Csato M, Dirnhofer S, Tzankov A (2009) BCL2 gene aberration as an IPI-independent marker for poor outcome in non-germinal-centre diffuse large B cell lymphoma. J Clin Pathol 62(10):903-907
42. Youssif C, Goldenbogen J, Hamoudi R, Carreras J, Viskaduraki M, Cui YX, Bacon CM, Burke GA, Turner SD (2009) Genomic profiling of pediatric ALK-positive anaplastic large cell lymphoma: a Children's Cancer and Leukaemia Group Study. Genes Chromosomes Cancer 48(11):1018-1026

43. Gupta S, Gupta R, Singh S, Gupta K, Kudesia M (2009) Nuclear morphometry and texture analysis of B-cell non-Hodgkin lymphoma: utility in subclassification on cytosmears. Diagn Cytopathol (in press)

44. Das P, Iyer VK, Mathur SR, Ray R (2009) Anaplastic large cell lymphoma: a critical evaluation of cytomorphological features in seven cases. Cytopathology (in press)

45. King RL, Pasha T, Roullet MR, Zhang PJ, Bagg A (2009) IMP-3 is differentially expressed in normal and neoplastic lymphoid tissue. Hum Pathol 40(12):1699-1705

46. Gujral S, Polampalli SN, Badrinath Y, Kumar A, Subramanian PG, Nair R, Gupta S, Sengar M, Nair C (2009) Immunophenotyping of mature B-cell non Hodgkin lymphoma involving bone marrow and peripheral blood: critical analysis and insights gained at a tertiary care cancer hospital. Leuk Lymphoma 50(8):1290-1300

47. van Rijk A, Svenstroup-Poulsen T, Jones M, Cabeçadas J, Cigudosa JC, Leoncini L, Mottok A, Bergman CC, Pouliou E, Dutoit SH, van Krieken HJ (2009) Double staining CISH as a useful alternative to split-signal FISH in lymphoma diagnostics. Haematologica (in press)

48. Monaco SE, Teot LA, Felgar RE, Surti U, Cai G (2009) Fluorescence in situ hybridization studies on direct smears: an approach to enhance the fine-needle aspiration biopsy diagnosis of B-cell non-Hodgkin lymphomas. Cancer Cytopathol 117(5):338-348

49. Zhang D, Saunders CJ, Zhao W, Davis M, Cunningham MT (2009) The clonality of CD3 + CD10+ T cells in angioimmunoblastic T cell lymphoma, B cell lymphoma, and reactive lymphoid hyperplasia. Am J Hematol 84(9):606-608 